\title{
A Review on Optimal Reactive Power Dispatch
}

\author{
Vismay Loriya ${ }^{1}$, Prof. Vishnu Patel $^{2}$ \\ PG Scholar, Electrical Engineering, Ganpat University, Kherva, India ${ }^{1}$ \\ Assistant Professor, Electrical Engineering, Ganpat University, Kherva, India ${ }^{2}$
}

\begin{abstract}
A voltage profile at load busses can be kept with appropriate limits by adequate reactive power support. Reactive power also plays a key role in supporting the real power flow to maintain voltage stability and system reliability. It is difficult for transmission system operator to minimize the cost associated with optimal reactive power dispatch along with technical constraint. In recent years, several evolutionary computing based optimization techniques are proposed and practiced to solve various issues involved in optimal reactive power dispatch problem. The ORPD problem has been solved as a single objective as well as multi-objective optimization problem using various conventional techniques as well as recent techniques including genetic algorithm, artificial bee colony, particle swarm optimization and differential evolution etc. This paper is a attempt to understand various concept involved in reactive power dispatch and to present a different work carried out by the various researchers in this field by using evolutionary computing based techniques.
\end{abstract}

Keywords: Optimal reactive power dispatch, genetic algorithm, artificial bee colony, particle swarm optimization, differential evolutionary programming, evolutionary technique.

\section{INTRODUCTION}

Complex electrical power is drawn in power system. Active power is the rate at which energy is lost or consumed.Reactive power is the rate at which the energy supplied 'circulates' in the system, Reactive power is useful in maintaining voltage levels stable.Reactive power plays an important role in supporting the real power transfer by maintaining voltage stability and system reliability so that necessary to optimize the reactive power dispatch. In this this paper presents a brief literature review of the optimal reactive power dispatch. The main objectives of optimal reactive power dispatch problem areto reduce the real power losses, to improve the voltage profile, system cost and to maximize the voltage stability of the power system. Various researchers are work on optimal reactive power dispatch problem by using different Technique like asgenetic algorithm, artificial bee colony, particle swarm optimization and differential evolution etc.

\section{REACTIVE POWER AS AN ANCILLARY SERVICE}

In a deregulated power system, the responsibility ofthe Independent System Operator is to maintain system reliability and security by providing for ancillary services. Ancillary service such as reactive power support, spinning reserves, energy balancing and frequency regulation.Sufficient reactive power support is necessary to be provided inthe system. The reactive power is maintain the power flow limits on transmission lines and voltage limits at bus bars.

In many deregulated power system the independentgenerators is continue to provide reactive power support without getting paid from the ISO. Onthe other hand, in some markets a mechanism provided for payment for reactive power support.

The deregulated electricity markets across different countries- how reactive power is managed. In UK, the

National Grid Company, which carried out the functions of the ISO and NGC isinvites tenders for reactive support services. The generators can bid for reactive power support through bids composed of capacity components and anutilization component. The selected bidders get into annual bilateral contracts with NGC and are it is paid for both the capability and utilization components [1].

In the New York system, the ISO (NYISO) isresponsible for providing reactive power support service, and the service is provided at embedded cost-based prices. Generating resources, which operate within their capability limits, are directed by the IS0 to produce or absorb reactive power to maintain voltages within limits.[2]

The Australian electricity market and its IS0 (NEMCO)also recognizes reactive power as an ancillary service andfinancial compensation is provided to generators andsynchronous compensators for their service provisions [3].

The reactive support providers are eligible for the availability payment component- for their preparedness for providing the service when called for. Synchronous compensators also receive the enabling payment componentpaid when their service is activated by the ISO for use. Onthe other hand a generator receives the compensationpayment component andwhich is based on its opportunity cost and paid when it has been constrained from operating according to its market decisions.

\section{REACTIVE POWER MANAGEMENT}

Reactive Power Management is one of themost important tasks for proper operation and control of a power system. Reactive Power Management reduces power system losses by adjusting the reactive power control variables such as generator voltages, transformer tap-settings and other sources of reactive power such as capacitor banks or FACTS devices. Reactive power management provides 
better system voltage control resulting in improved voltage method etc. were used for solving the optimal reactive profile, system security, power transfer capability and power dispatch problem.In recent years, evolutionary overall system operation. Many researchers are work on techniques such as genetic algorithm, differential Reactive power management and manage to reactive evolution, particle swarm optimization and artificial bee power using different method.

In [4], this paper present compares SVC with fixed capacitor compensation and superiority of SVC using Computer Simulation and its performance for reactive power management and better voltage control. Flexible A.C. Transmission System promotes the use of static controllers to enhance the controllability and increase the power transfer capability. The simulation result of SVC and this results are obtain using PSCAD/EMTDS, after that conclude that SVC effectively use tocontrol voltage and reactive power compensation.SVC has much superior voltage control capabilitiesboth, in steady and transient state than the conventionalswitched shunt capacitor and reactor compensation.

\section{REACTIVE POWER PROCUREMENT}

Voltagestability has become a major concern in present day power system operation which depends on the availability and distribution of reactive power. It becomes very important to ensure sufficient amount of reactive power source in the network for secure and reliable operation of electrical power system. Reactive power procurement problem is established in real power market. This paper presents three new Reactive power procurement methods which are formulated as optimum power flow problems. First optimal power flows are solved using Artificial Bee Colony algorithm. This algorithmis population based stochastic solution methods and itsmore suitable for solving reactive power optimization problem.

Second, a detailed analysis of voltage stability for proposed Reactive power procurementproblems are performed for both normal and contingency condition and find out how these new formulations affect voltage stability.

Third, proposed methods are compared with the classicalReactive power procurement formulations, e.g., Minimization of L-index and loss Minimization. These methods are tested on IEEE 30 bus system and 508-Bus Indian System.

\section{OPTIMAL REACTIVE POWER DISPATCH}

Optimal power flow is a main concern in the power systems. This problem can be divided into two sub problems, real power and reactive power dispatch [6].

In the power system, optimal reactive power dispatch problem is very challenging optimization problem. Reactive power also plays a key role in supporting the real power flow to maintain voltage stability and system reliability. Optimal reactive power dispatch is required to control generator voltage, transformer tap setting, and static VAR sources [8].The real and reactive powers of a power system can be controlled by angle of bus voltage and voltage magnitude respectively [7].

In the past decades, quadratic programming, linear programming, non-linear programming and interior point colving optimal reactive power dispatch problem [10].

Genetic Algorithm is an optimization method, which is based on mechanics of natural selection and natural genetic. Differential Evolution algorithm is a population based algorithm, and in this create off- spring from parent chromosomes applying differential operator. Artificial Bee Colony is an optimization algorithm based on honey bee swarm intelligent behaviour. The Particle Swarm Optimization is considered as realistic and powerful scheme for obtain the global optimum solution of reactive power problem.

Optimal reactive power dispatch problem has been solved by single-objective optimization problem as well as multi objective optimization problem. The single objective optimization has only one objective function whereas multi-objective optimization hasa set of objective functions [9].

A. Optimal reactive power dispatch as a single objective optimization problem

Optimal reactive power dispatch problem has been solved by the various researchers as a single reactive optimization problem for minimize the transmission loss, for improve voltage profile, for minimize the system cost and for improvevoltage security.

\section{Loss minimization}

Optimal reactive power dispatch problem has been solved by the various researchers and objective function is aimed to minimize the transmission lossand in this paper take a control variable like as a generator bus voltages, transformer taps and capacitors banks. The equality constrains include the power flow equations and inequality constrains include the bus voltage limits, generator reactive power limits, reactive power capacity limits, and transformer tap position.[11]-[15]

In most of papers [11]-[14]objective function is aimed to minimize the transmission active power loss by using eq(1)

$$
\begin{gathered}
\operatorname{Min} \mathrm{f}=\sum_{\mathrm{k}=1}^{\mathrm{N}_{\mathrm{B}}} \mathrm{P}_{\text {Loss }_{\mathrm{k}}}=\sum \mathrm{g}_{\mathrm{m}}\left[\operatorname{tap}_{\mathrm{t}}\left(\mathrm{V}_{\mathrm{i}}\right)^{2}+\left(\mathrm{V}_{\mathrm{j}}\right)^{2}-\right. \\
2 \operatorname{tapt}(\mathrm{Vi})(\mathrm{Vj}) \cos \theta \mathrm{ij} \ldots \ldots(1)
\end{gathered}
$$

In [11]differential evolutionary algorithm was tested on IEEE 14, 30, 57 and 118-Bus systems and the results were compared with popular particle swarm optimization and conventional interior point method. While In [15], The proposed algorithm was tested on IEEE 14 and their results were compared to that obtain using Genetic algorithm and Linear programming method. $\operatorname{In}[14]$ the minimize the losses using genetic algorithm and proposed algorithm was tested on IEEE 14 and 30 bus systems and their result compared with loss minimize using genetic algorithm and using load flow calculation. In [13]proposed algorithm was tested on IEEE 14 and their results were compared with loss minimizationusing Genetic algorithm and Linear programming method. 
While In[12], Minimize the losses using eq (2). The Here, $F_{L G}=-\left|Y_{L L}\right|^{-1} F_{L G}$

SARGA was tested on both IEEE 14 and IEEE 30 bus system to demonstrate the applicability and efficiency of this method. The result of minimization of losses compared with SARGA and evolutionary programming. The problem was formulated as follows: [9]

$$
\begin{gathered}
\text { Min } f=\sum_{k=1}^{N_{B}} P_{\text {Loss }_{k}}+\lambda_{P G}\left|P_{G}-P_{G l i m}\right|+\lambda_{Q G} \mid Q_{G}- \\
\text { QGlim...(2) }
\end{gathered}
$$

Where $\lambda_{P G}$ is the penalty factor for the active power slack bus when producing out limits $\left(P_{\text {Glim }}\right)$ and $\lambda_{Q G}$ is the penalty factor concerning generators reactive power limits $\left(Q_{\text {Glim }}\right)$

\section{Voltage Profile Improvement}

The optimal shunt capacitor planning of a transmission system using genetic algorithm is implemented in [8]. The main purpose of in this paper is to decide the setting number of shunt reactor units of each bus and to optimize the bus voltage. In reactive power dispatch, the goal we defined is the 1.0 p.u. of bus voltage. In order to reach the goal, the penalty factors are used for voltage-fall or voltage-rise buses. thefitness function is designed in eq (3)

$$
\text { Minimize } \sum\left|V_{i}-1\right| * f\left(V_{i}\right) \ldots .(3)
$$

Where, the bus $V_{i}$ is considered for all of buses except PV bus.

Chao-Rong Chen author [15] is improving the voltage profile using eq (3). Goal of the both papers [8] and [15] are the same, technique using in these papers for achieving goal also same but main difference in paper [15] is compared the simulation results to original genetic algorithm and found improved results of modified genetic algorithm.

\section{Voltage Stability Enhancement}

Voltage stability analysis involves both static and dynamic factors. As dynamic computations are time consuming so that static approach is generally preferred for stability assessment and control.

Static voltage stability analysis involves determination of an index called voltage stability index. This index is an approximate measure of closeness of the system to voltage collapse. There are various methods of determining the voltage stability index.

Thispaper presents voltage stability enhancement using improved Genetic algorithm and it wastested on IEEE 30 bus system and 75 bus system. The proposed technique is based on the minimization of L-indices of load buses.It is based on load flow analysis. The L-index calculation for a power system is briefly discussed below:

Consider a N-bus system in which there are $\mathrm{Ng}$ generators. The relationship between voltage and current can be expressed by the following expression:

$$
\left[\begin{array}{c}
I_{G} \\
I_{L}
\end{array}\right]=\left[\begin{array}{cc}
Y_{G G} & Y_{G L} \\
Y_{L G} & Y_{L L}
\end{array}\right]\left[\begin{array}{l}
V_{G} \\
V_{L}
\end{array}\right]
$$

Rearranging the above equation we get,

$$
\left[\begin{array}{l}
V_{L} \\
I_{G}
\end{array}\right]=\left[\begin{array}{ll}
Z_{L L} & F_{L G} \\
K_{G L} & Y_{G G}
\end{array}\right]\left[\begin{array}{c}
I_{L} \\
V_{G}
\end{array}\right]
$$

The L-index of the jth node is given by the expression,

$$
L_{j}=\left|1-\sum_{i=1}^{g} F_{j i} \frac{V_{i}}{V_{j}} \quad \angle\left(\theta_{i j}+\delta_{i}-\delta_{j}\right)\right| .
$$

where $V_{i}, V_{j}$ are the voltage magnitude of ith and jth generator, $\theta_{i j}$ is phase angle of the $F_{j i}$ term, $\delta_{i}, \delta_{j}$ are the voltage phase angle of ith and jth generator unit. The values $F_{j i}$ of are obtained from $F_{L G}$ the matrix.

M. Sailaja kumara author [20] isintroduced optimal power flow and its results compare with using Genetic algorithms and using Particle Swarm Optimization and methods was applied in the IEEE 30-bus system to find out the optimal power flow. The control against voltage collapse is based on minimizing the sum of squared L-indices for a given system operating condition.[20]

$$
\mathrm{J}=\sum_{j=g+1}^{n} L_{j}^{2} \ldots(7)
$$

Where $\mathrm{g}$ is the number of generator buses, $\mathrm{n}$ is the total no. of buses in system.

$$
L_{j}=\left|1-\sum_{i=1}^{\mathrm{g}} F_{j i} \frac{V_{i}}{V_{j}}\right| \mathrm{j}=\mathrm{g}+1 \ldots \ldots . . \mathrm{n}
$$

All the quantities with in sigma in RHS of (8) are complex quantities. The value of $F_{j i}$ are obtained from $\mathrm{Y}$ bus matrix.

\section{Cost Minimization}

In [22], minimize the cost of reactive power from generator and reactive power compensators. To find the payment to generators and reactive compensators and result obtained using Genetic algorithm. The proposed method is applied on IEEE 14 bus system.

First cost is Reactive cost of generator is presented as follows.

$$
\left.C_{\text {gpi }} Q_{\text {gi }}=\left[C_{\text {gpi }} S_{\text {gi max }}-C_{\text {gpi }}\left(\sqrt{\left(S_{\text {gi max }}^{2}-Q_{\text {gi }}^{2}\right.}\right)\right)\right] k_{\text {gi }} \ldots
$$

A quadratic function

$$
\mathrm{C}_{\text {gpi }} \mathrm{P}_{\mathrm{gi}}=\mathrm{aP}_{\mathrm{gi}}^{2}+\mathrm{bP}_{\mathrm{gi}}+\mathrm{c}
$$

Where, $P_{\text {gi }}$ is the active power output of $g_{i}$

$a, b, c$ are cost coefficient

Second Cost is cost reactive compensators is proportional to the amount of reactive power purchased and can be expressed as :-

$$
C_{c j} Q_{c j}=r_{j} Q_{c j}
$$

where, $r_{j}=$ reactive cost

$\mathrm{Q}_{\mathrm{cj}}=$ reactive power purchased

Minimize the both cost by following expression:-

$$
\text { Min } \mathrm{C}_{\mathrm{Q}}=\sum_{\mathrm{i} \in \mathrm{N}_{\mathrm{G}}} \mathrm{C}_{\mathrm{gpi}} \mathrm{Q}_{\mathrm{gi}}+\sum_{\mathrm{i} \in \mathrm{N}_{\mathrm{c}}} \mathrm{C}_{\mathrm{ci}} \mathrm{Q}_{\mathrm{ci}} \ldots
$$

Where, $C_{Q}$ is total reactive support cost from generator and compensators, $\mathrm{N}_{\mathrm{G}}$ is set of all generator, $\mathrm{N}_{\mathrm{c}}$ is set of all compensator buses. 
In [21], The optimal power flow solution is obtained with and proposed multi objective approach. The result show fuel cost minimization as the objective function, Optimal that multi objective approach method achieves the best power flow can be formulated for reactive power result for optimal power flow. [25] optimization. The proposed method was applied in the IEEE 30-bus system to find out the optimal power flow. The optimal power flow results obtained using Genetic algorithms and Particle Swarm Optimization was compared.

Fuel cost minimize by following expression:-

$$
\mathrm{J}=\sum_{\mathrm{i}=1}^{\mathrm{g}} \mathrm{f}_{\mathrm{i}} \ldots \text { (13) Where, } \mathrm{f}_{\mathrm{i}}=\mathrm{a}_{\mathrm{i}}+\mathrm{b}_{\mathrm{i}} \mathrm{P}_{\mathrm{Gi}}+\mathrm{c}_{\mathrm{i}} \mathrm{P}_{\mathrm{Gi}}^{2}
$$

$a_{i}, b_{i}, c_{i}$ are the cost coefficient of unit $i$

$\mathrm{g}$ is number of generator

$\mathrm{P}_{\mathrm{Gi}}$ ia real power generation of unit $\mathrm{i}$

\section{CONCLUSION}

Reactive power dispatch isand optimization problem require solving by considering various technical and economical points. This paper gives and overview of numerous works carried out in this area. Various optimization techniques used by researchers and different objective functions proposed by them are studied. Attempts made by many countries like US, UK, Australia for optimal reactive power management is also discussed. The authors believe that discussion had under various sections will help full to research community in this area.

\section{B. Optimal reactive power dispatchas a multi objective optimization problem}

\section{REFERENCES}

The researchers have solved optimal reactive power dispatch problem as a multi objective optimization problem and mostly following objective function are consider in different papers like as loss minimization, voltage profile improvement, system cost minimization and for voltage stability improvement. Objective function are achieved by proper adjustment of reactive power variables like generator voltage magnitude, reactive power generation of capacitor bank, and transformer tap setting. Power flow equations are the equality constraints of the problems, while the inequality constraints include the limits on real and reactive power generation, bus voltage magnitudes, transformer tap positions and line flows.

P. ArunaJeyanthy author is introducing Reactive power optimization Inclusing Voltage Stability. Optimize the reactive power dispatch problem is carried out by multi objective genetic algorithm, Objective function of reactive power optimization are minimization of the losses and maximization of the voltage stability margin.Genetic algorithm was tested on IEEE 30-bus and IEEE 57-bus test system. The simulation results are compared with Evolutionary programming, Simple Genetic algorithm and Multi objective genetic algorithm .The result showed that the Multi objective genetic algorithm based approach achieves the best results for solving the multi objective reactive power optimization problems [23].

M.A.Abidoaurthor is introduce the multi objective optimal reactive power dispatch. The optimal reactive power dispatch problem is formulated as multi objective optimization problem where real power loss and voltage stability are to be optimized. In this paper[24] strength pareto evolutionary algorithm is used for solving the multi objective reactive power dispatch problem and this algorithm was tested on IEEE 30 bus system and Wale hale 6 bus system.[24]

M.A.Abidoauthor is introduce the novel multi objective evolutionary algorithm for a optimal power flow. The optimal power flow is formulated as multi objective optimization problem where objective function consider as a fuel cost minimization and voltage stability index are to be minimized.The problem is solved out by usingstrength pareto evolutionary algorithm and it was tested on IEEE 30-bus.The results compared with individual optimization

[1] S. Ahmed and G. Strbac, "A method for simulation and analysis of reactive power market', proceedings of Power Industry Computer Applications Conference 1999, pp.337-341.

[2] "NYISO Ancillary Services Manual 1999", available fromhttp://www.nyiso.com

[3] National Electricity Market Management Company (Australia), "National electricity market ancillary services", Version1.0.November1999, http://www.necmo.com

[4] PravinChapadel, Dr. Marwan Bikdash,Dr.IbraheemKateeb,Dr.Ajit D. Kelkar "Reactive Power Management and Voltage Control oflarge Transmission system using SVC" Southeastcon ,2011 proceeding IEEE

[5] Mala De, and Swapan K. Goswami "Optimal Reactive Power Procurement With VoltageStability Consideration in Deregulated Power System" IEEE transactions on power systems, vol. 29, no. 5, 2014

[6] Saied Salamat Sharif, "Optimal Reactive Power Flow Problem", Msc Iran University of Science and Technology, Sept.1987.

[7] Chao-Rong Chen, Hang-Sheng Lee, Wenta Tsai "Optimal Reactive Power Planning Using Genetic Algorithm", in proceedings of the Systems, Man and Cybernetics, IEEE International Conference, vol. 6, pp. 5275-5279, Oct. 2006.

[8] Yong-jun Zhang, Zhen Ren "Real-time optimal reactive power dispatch using multi-agent technique", International Journal of Electric Power Systems Research, vol. 69, pp. 259-265, May 2004.

[9] Congyu Zhang, Minyou Chen and CiyongLuo "A Multi-objective Optimization Method for Power System Reactive Power Dispatch", in proceedings of the Intelligent Control and Automation (WCICA), $28^{\text {th }}$ World Congress, pp. 6-10, July 2010.

[10] A.A. AbouEla, M.A. Abido, S.R. Spea "Differential evolution algorithm for optimal reactive power dispatch", International Journal of Electric Power Systems Research, vol. 30, pp. 435-441, Oct. 2008.

[11] M. Varadarajan, K.S. Swarup "Differential evolutionary algorithm for optimal reactive power dispatch", International Journal of Electrical Power and Energy Systems, vol. 30, pp. 435-441, Oct. 2008.

[12] P. Subbaraj, P.N. Rajnarayanan "Optimal reactive power dispatch using self-adaptive real coded genetic algorithm", International Journal of Electric Power Systems Research, vol. 79, pp. 374-381, February 2009

[13] Zita A. Vale, Carlos Ramos, Marcro R. Silva , Bruno Canizes, Tiago Sousa and Hussein M. Khodr " Reactive power compensation by EPSO technique." System Man and Cybernetics (SMC), 2010 IEEE international Conference ,pp. 1512-1518

[14] W.N.W Abdullah, H. Saibon A.A.M Zain, K.L. Lo "Genetic Algorithm for Optimal Reactive Power Dispatch", in proceedings of the Energy Management and Power Delivery, International Conference, vol. 1, pp. 160-164, march 1998.

[15] Chao-Rong Chen, Ching-Yin Lee, Yen-Fung Hsu, Hai-Wen Chao "Optimal Reactive Power Dispatch of Power Systems Using a Modified Genetic Algorithm", in proceedings of the Power System Technology, International Conference, vol. 2, pp. 1266-1269, Nov 2004. 
[16] C. Thammasirirat, B. Marungsri, R. Oonsivilai, and A. Oonsivilai "Optimal Reactive Power Dispatch using Differential Evolution", World Academy of Science, Engineering and Technology, pp. 8994, 2011.

[17] S. Durairaj, P. S. Kannan and D. Devaraj "Application of Genetic Algorithm to Optimal Reactive Power Dispatch including Voltage Stability Constraint", Journal of Energy \& Environment, vol. 4, pp. $63-73,2005$.

[18] K. Vaisakh, P. Kanta Rao "Differential Evolution Based Optimal Reactive Power Dispatch for Voltage Stability Enhancement", Journal of Theoretical and Applied Information Technology, vol. 4, pp. 700-709, 2008.

[19] D. Devaraja, J. Preetha Roselyn "Genetic algorithm based reactive power dispatch for voltage stability improvement", International Journal of Electrical Power and Energy Systems, vol. 32, pp. 11511156, Dec 2010

[20] M.SailajaKumari, G.Priyanka, M.Sydulu "Comparison of Genetic Algorithms and Particle Swarm Optimization for optimal power flow Including FACTS devices." Power Tech 2007 IEEE Lausanne , pp. $1105-1110$

[21] P. ArunaJeyanthy and Dr. D. Devaraj "Optimal Reactive Power Dispatch for Voltage Stability Enhancement Using Real Coded Genetic Algorithm", International Journal of Computer and Electrical Engineering, vol. 2, pp. 1793-8163, August, 2010.

[22] R.Suresh and N. Kumarappan"Genetic Algorithm based Reactive power Optimization under Deregulation" International Conference on Information and communication technology in Electrical Science 2007, pp.150-155

[23] P. ArunaJeyanthy, D. Devaraj "Multi-Objective Genetic Algorithm for Reactive Optimization Inclusing Voltage Stability", International Journal of Engineering Science and Technology, vol. 2 (7), pp. 2715- 2729, Oct 2010.

[24] M.A.Abido "multi objective optimal reactive power (VAR) dispatch problem using strength pareto evolutionary algorithm" Evolutionary Computation. CEC. IEEE Congress on 2006 ,pp. 730736

[25] M.A. Abido "Multi objective optimal power flow using StrengthPareto Evolutionary Algorithm." Universities Power Engineering Conference 2004. 